\title{
O ESTUDO DO MERCADO IMOBILIÁRIO EM CIDADES MÉDIAS: PROCEDIMENTOS PARA COLETA E SISTEMATIZAÇÃO DOS DADOS
}

\author{
STUDY OF REAL STATE MARKET IN MEDIUM-SIZED CITIES: \\ PROCEDURES FOR DATA COLLECTION AND SYSTEMATIZATION
}

\author{
Marlon Altavini de Abreu \\ Mestrando em Geografia \\ FCT-UNESP \\ marlon_altavini@hotmail.com \\ Wagner Vinicius Amorim \\ Doutorando em Geografia \\ FCT-UNESP \\ wagner_g3@yahoo.com.br
}

\begin{abstract}
RESUMO
O presente artigo propõe-se ao debate dos procedimentos pertinentes ao estudo da oferta no mercado imobiliário em cidades médias. Enfatiza as potencialidades e as limitações oriundas dos classificados imobiliários como principal fonte de dados. Utiliza-se de exemplos de pesquisas desenvolvidas, discutindo formas de análise e interpretação, através da mediação empírica e das questões associadas ao modo tal como agentes econômicos, circunscritos à dimensão do mercado imobiliário, produzem e comercializam frações do espaço urbano. Para tanto, apresenta os resultados desenvolvidos a partir do estudo do mercado imobiliário das cidades de Londrina/PR, Marília/SP e São José do Rio Preto/SP, destacando as variáveis, as escalas de análise, as formas de tratamento dos dados e o modo de sua representação.
\end{abstract}

Palavras-chave: mercado imobiliário; dinâmica imobiliária; classificados imobiliários; valorização urbana; cidades médias.

\begin{abstract}
This article proposes a discussion of procedures pertinent to the study of the real estate market in middle-sized cities. Emphasizes the potential and limitations arising from real estate classified as a primary data source. Is used examples of research conducted, discussing ways of analysis and interpretation, through mediation and empirical issues related to the way such as economic agents, restricted to the size of the real estate, produce and sell fractions of urban space. It presents the results developed from the study of real estate market in the cities of Londrina/PR, Marilia/SP and São José do Rio Preto/SP, detaching the variables, scales of analysis, processing of the data and the way its representation.
\end{abstract}

Keywords: real estate; real estate dynamics; estate-sales classifieds; valuation urban; middle-sized cities. 


\section{Introdução}

O presente trabalho ${ }^{1}$ propõe-se à discussão das fontes de dados e procedimentos para análise do mercado imobiliário. Partindo de exemplos concretos de pesquisas desenvolvidas, estabelece considerações em torno dos desafios de pesquisas alçados à construção de uma sistemática de análise capaz de captar a variação dos preços, tipos e a localização da oferta imobiliária em cidades médias e/ou de porte médio.

Ressalta-se que não é nosso objetivo problematizar os resultados de pesquisa obtidos, mas sim destacar as formas de utilização e as correlações possíveis com o material empírico coletado em sua organização e exposição por meio de gráficos, tabelas e mapas, destacando as potencialidades e limitações próprias à elaboração de procedimentos de análise formulados a partir de um amplo e adequado banco de dados com base nos anúncios de classificados imobiliários de jornal. Portanto, a pesquisa em detalhe será tomada como suporte para discutir os procedimentos de análise para um estudo comparativo dos mercados imobiliários destas cidades.

O progresso associado à construção da pesquisa empírica e ao rigor atrelado aos procedimentos metodológicos de coleta e organização do material empírico demanda, em sua elaboração, preocupações analíticas subjacentes às escalas, agentes e processos relacionados à produção do espaço urbano, tal como indicado por Melazzo (2012) ao explicitar sua preocupação lançada às pesquisas voltadas para as realidades não metropolitanas, com destaque as cidades médias brasileiras.

Neste sentido, o rigor com relação as fontes de dados agrega, em sua seleção, preocupações subjacentes tanto às formas de mediação empíricas como ao trato teórico de questões associadas ao modo tal como agentes econômicos, circunscritos à dimensão do mercado imobiliário, produzem e comercializam frações do espaço urbano.

Estas discussões ganham forma e respaldo através das ações integradas em uma agenda maior de investigações, que tem por foco a pesquisa empírica assumida como subsídio para a construção teórica e conceitual da compreensão das cidades médias brasileiras. Trata-se, especificamente, dos estudos desenvolvidos pela Rede de Pesquisadores sobre Cidades Médias (ReCiMe), e pelo Grupo de Pesquisa Produção do Espaço e Redefinições Regionais (GAsPERR). 
A partir dos resultados obtidos por meio das pesquisasdesenvolvidas nas cidades de Londrina/PR, em Amorim (2011a), e em Londrina/PR, Marília/SP e São José do Rio Preto/SP, em Abreu (2011), apresenta-se um conjunto sistematizado de procedimentos para coleta,sistematização e leitura dos dados. Neste sentido, a discussão que ora se propõe, abarca, em sua amplitude, origor associado aos procedimentos decompilação e processamento de dados referentes aos tipos de produtos imobiliários, ao volume ofertado, aos agentes de comercialização e aos preços médios praticados em cada uma destas cidades.

\section{Os anúncios de jornais: procedimentos de coleta de dados e formas de análise}

A presente secção apresenta os procedimentos metodológicos para a seleção, coleta, organização e tratamento do material empírico para o estudo do mercado imobiliário em cidades médias ou de porte médio. Especificando neste conjunto de ações, circunscritos pelos diferentes momentos da elaboração da pesquisa, questões pertinentes à seleção e avaliação das variáveis e procedimentos de análise ${ }^{2}$.

Neste sentido, situamos nosso entendimento de mercado imobiliário como lugar econômico da valorização de capitais em que se realizam transações de compra e venda de imóveis - edificados ou não - e que, em sua dinâmica, evidencia uma forma de organização peculiar, ancorada nas formas de reprodução do capital, demarcadas no tempo e no espaço e que podem estar associadas a momentos de transformações intraurbana e interurbanas. (MELAZZO, 1993).

Assim, é importante reconhecer que o mercado imobiliário resguarda, em sua constituição, particularidades que lhe são próprias,em função da natureza das mercadorias ofertadas, das formas de valorização e da concentração do mercado ${ }^{3}$.

Destas particularidades, desdobram-se constrangimentos às ações direcionadas a pesquisa e leitura, isto porque, a falta de transparência e de informações rápidas e atualizadas sobre que tipo de produto imobiliário, onde e a que preço, os tributos recolhidos em cada transação ou mesmo os valores cobrados nominal e efetivamente de cada imóvel, acabam por gerar distorções sistemáticas que possibilitam e favorecem a existência de informações para poucos (incorporadores, loteadores etc.) e, consequentemente, sobrelucros em suas operações e estratégias especulativas em períodos e áreas determinadas. 
Neste sentido, a carência, ou mesmo limitações atinentes às fontes de informação para o mercado imobiliário são uma realidade da pesquisa, o que ocorre em função da constituição de um mercado pouco transparente, marcado pela escassez e precariedade das informações registradas nas prefeituras municipais, da dificuldade de acesso aos Cartórios de Registros de Imóveis ou Receita Federal (ver CESARE; CUNHA, 2012). Associada a escassez e informalidade, é destacada a dificuldade na obtenção e organização de dados confiáveis e representativos para a constituição de um estudo mais amplo, ou seja, que possa oferecer comparabilidade destes dados em diferentes anos e entre diferentes cidades. Neste sentido, uma análise minimamente abrangente, deve dispor de informações atualizadas sobre um conjunto de variáveis pertinentes à análise comparativa, contemplando: o tipo de produto imobiliário, sua localização, seus agentes de comercialização e preço.

Para tanto, os anúncios de classificados em jornais de circulação local foram adotados como fonte base para este estudo. Este procedimento de análise é pautado pela viabilidade da coleta deste material, já que as cidades analisadas possuem um - ou mais - jornal local de circulação diária e de acesso possível, seja na própria sede do jornalou nos arquivos de bibliotecas.

Entretanto, a escolha desta fonte de dados demanda cuidados em sua interpretação, sobretudo nos significadosdas ofertas de imóveis no conjunto do mercado imobiliário. É importante reconhecer que este recurso utilizado na coleta de material empírico não é a única forma de se agrupar informações acerca do mercado imobiliário e nem apresenta a condição de abarcar a totalidade das transações conferidas no período estudado (CESARE; CUNHA, 2012).

$\mathrm{Na}$ verdade, os anúncios de classificados em jornais, expressa uma composição peculiar já que se trata unicamente do preço de oferta do imóvel, encerrando em sua composição um preço que condiz com expectativas de venda desejada e não necessariamente o preço final. Estas expectativas correspondem a intenções de venda que podem ou não realizar-se. Além disso, os anúncios sinalizam uma fração de mercado em que predominam as ofertas de imóveis usados, sendo restritas ou poucas as informações voltadas aos lançamentos e novos produtos imobiliários, ou daqueles de maior e menor preço cuja divulgação não ocorre, majoritariamente, no âmbito dos classificados imobiliários em jornais. 
Entretanto, mesmo no contexto das limitações de sua própria natureza, esta fonte de dados envolve um conjunto amplo e variado de anunciantes, e é capaz de abarcar um recorte temporal significativo. Além disso, torna possível a comparação entre outras cidades, constituindo-se assim numa fonte comum de pesquisa, ao possibilitar a percepção das tendências de valorização desigual no interior das cidades e, numa análise comparada, verificar a variação dos preços de imóveis em cada uma delas em um mesmo período de análise.

Ademais, a fonte dos jornais é a única possível de ser obtida sem o recurso a tantas viagens, podendo ser reunida em uma única visita por um determinado pesquisador, com levantamento sistematizado dos classificados desejados. Esta estratégia demonstra que se pode estudar a dinâmica dos preços sem o recurso a inumeráveis classificados de jornais, selecionando-se determinados mesese desses meses extraindo os classificados do domingo, dia de maior quantidade de anúncios. Ou ainda, analisando-se cada mês do ano, selecionando um domingo ao mês, ganhando-se em amplitude por um lado, mas perdendo-se em acurácia, por outro.

Nestas condições, é preciso grande cautela no trato com os anúncios coletados, objetivando o enfoque atrelado às escolhas das informações que se deseja obter, estabelecendo um padrão claro de questionamentos lançados a cada um dos anúncios presentes nas páginas de jornal. Esta preocupação é devida em virtude da construção de um banco de dados capaz de armazenar o máximo de informações pertinentes ao enquadramento das ofertas imobiliárias coletadas, ao mesmo tempo em que deve abordar de maneira padronizada cada um dos anúncios, já que estes não se encontrampadronizados.

A seletividade presente na coleta destes materiais deve priorizar as informações mais comuns, correspondentes às questões fundamentais - O quê? Aonde? Quando? Qual uso? A que preço? E por quem? -, características dos imóveis que tornam evidentes a localização por bairros, zona, o tipo de imóvel comercializado (casa, apartamento ou terreno), seu uso (comercial, residencial, industrial ou misto), sua área total e área edificada, a imobiliária anunciante, o número de dormitórios e o preço de oferta.

O objetivo é examinar detalhadamente a importância de cada uma das variáveis, e relacioná-las ao processo de produção do espaço urbano, para além de critérios 
puramente quantitativos, mas atribuindo-se grande atençãoà metodologia e à pesquisa empírica, justificando as razões de cada uma destas variáveis.

No que se refere às variáveis relativas à temporalidade dos anúncios, destaca-se a amplitude das ofertas, aqual põe em evidência o tempo de circulação, de rotação e a temporalidade destes eventos na dinâmica do mercado, que não respeitam, necessariamente, mudanças de décadas, mas sim a conjuntura econômica nacional e imobiliária local. Por exemplo, pode-se ter situações em que a macroconjuntura econômica imponha um ritmo mais acelerado à circulação dos ativos no mercado imobiliário, ou simplesmente à compra e venda de imóveis, em contrapartida a períodos de baixa liquidez ou mesmo de arrefecimento no mercado imobiliário. Há também situações particulares em que o mercado imobiliário local possa impingir um ritmo aos negócios, demandando ao pesquisador a atenção com relação a essas especificidades que, inclusive, necessariamente não estão articuladas às anteriores. Mais que isso, é importante ter em mente a articulação escalar destes processos, e qual peso exerce cada uma destas "forças" na variação temporal dos negócios e das ofertas imobiliárias.

No contexto da pesquisa a partir dos classificados de imóveis há que se ter em mente que se trata de um olhar para o passado, de pesquisar o que já foi lançado no mercado, há muito ou pouco tempo. No entanto, sempre está se olhando para o passado, para aquilo que já foi produzido. Estamos observando mercadorias que estão dispostas à venda em momentos diferentes daquele datado de sua origem. Por isso é importante analisar a evolução dos lançamentos a partir das pesquisas de campo e compreender o tempo de circulação destamercadoria.

É sintomático algumas pesquisas periodizarem a temporalidade do mercado imobiliário de uma maneira cartesiana, isto é, subdividindo os períodos de análise em décadas, ou a cada cinco anos, ou ainda, adotando como marcos temporais fatos que remetam a eventos extralocais, quando, na verdade, os tempos e os eventos locais seriam mais apropriados. Mas essa escolha não é arbitrária, tendo mais a ver com uma articulação escalar, e depende do desenvolvimento da pesquisa, e dos dados mais importantes da realidade estudada, seja na escala local ou não. Estes dados da realidade podem ser, por exemplo: aprovação de planos e pacotes econômicos que beneficiem a construção civil, a habitação e a infraestrutura urbana, ou ainda, a criação e disponibilização de linhas de crédito e financiamento imobiliário. Na escala local podemos citar a construção de 
grandes empreendimentos e obras públicas carreadores da valorização imobiliária, como os chamados"vetores" de expansão imobiliária, oriundos tanto da economia privada como das ações públicas; ou a revisão da legislação urbanística, por exemplo, evidente na redefinição do perímetro urbano, do zoneamento e coeficientes construtivos, dentre outros.

As variáveis relativas à localização dos anúncios (loteamento/bairro/zonas) permitem uma caracterização criteriosa do predomínio dos tipos de imóveis com maior ocorrência em cada uma das áreas da cidade, enquadrando, no conjunto das informações compiladas, possibilidades diversas de análise e espacialização das ofertas. A espacialização destas ofertas permitirá um recorte escalar no qual é possível delimitar os anúncios numa divisão por bairros, privilegiando uma análise comparada das variações percebidas no interior da cidade, em que transparece, por exemplo, o tipo de imóvel ofertado de maior ocorrência em cada um dos bairros, ou mesmo o padrão construtivo de cada um deles, com destaque para o grau de segmentação do mercado.

Paralelamente, as espacializações por zonas urbanas permitem uma caracterização mais generalizada das ofertas, expondo, contudo, um movimento de concentração zonal dos tipos de imóveis, importante às análises comparativas, visto que torna possível identificar "setores" de valorização do mercado, evidenciando similaridades ou diferenças entre as estratégias de valorização desigual empregadas em diferentes áreas das cidades. Estas informações, associadas a uma base cartográfica adequada, que contenha as subdivisões dos bairros ou zonas urbanas, possibilitam a elaboração do mapeamento das formas de "organização" do mercado em suas estratégias de seletividade dos setores de expansão imobiliária, dos nichos de mercado, e a demonstração, por exemplo, da predominânciada verticalização em determinadas áreas, eda horizontalização do habitat em outras.

As variáveis relativas ao tipo de imóvel (terreno, casa ou apartamento), número de cômodos e/ou dormitórios e ao uso a que se destina o imóvel anunciado (residencial, comercial ou misto), evidencia como se encontra a composição das ofertas, e demonstra a consolidação e a estrutura do mercado em determinadas áreas da cidade.

As variáveis relativas à metragem/área do imóvel ofertado envolvem três aspectos que, apesar de semelhantes, já que intencionam evidenciar o tamanho em $\mathrm{m}^{2}$ do imóvel 
ofertado, apresentam algumas distinções no que tange à especificidade desta metragem, exigindo um maior detalhamento dos anúncios compilados.

Neste sentido, a variável área do terreno está vinculada a metragem total em metros quadrados do lote anunciado. A variável área construída está normalmente atrelada aos anúncios de casas e apartamentos e diz respeitoà metragem da área edificada no lote. Por fim, a área totaldiz respeito às informações específicas aos apartamentos e residências em loteamentos fechados, e, diferentemente da área construída ou útil, considera o papel do condomínio, ou seja, dos equipamentos de lazer, esportivos, garagem e espaços comunais existentes.

Com relação aos agentes anunciantes do mercado imobiliário, o primeiro aspecto a enfatizar é o de que há uma pluralidade de agentes atuando distintamente, seja com relação às práticas, estratégias e/ou ao marketing e publicidade adotados. Diferem também com relação à sua organização profissional e empresarial: as imobiliárias, as construtoras, as incorporadoras, os corretores particulares, e demais formas de atuação, nas quais, por exemplo, pode-se verificar uma mesma empresa assumindo duas ou mais funções, trabalhando individualmente ou em parceria com outras empresas - inclusive, possuindo um jornal comum específico de classificados imobiliários. Entretanto, no âmbito dos classificados imobiliários, predominam as ofertas centralizadas pelas imobiliárias, e em menor âmbito os anúncios particulares.Há imobiliárias que se voltam a determinados tipos de produtos, em detrimento de outros, e privilegiam certas localizações mais dinâmicas do ponto de vista do mercado imobiliário, agindo, assim, seletiva e exclusivamente.

A variável preço completa o banco de dados em seu conjunto, e oferece a base relacional com as demais variáveis, principalmente aquelas referentes à localização e metragem do imóvel. Entretanto, resguarda alguns cuidados para que sejam evitadas distorções quando relacionadas entre si. Todos os preços por $\mathrm{m}^{2}$ devem ser deflacionados, utilizando a correção dos valores segundo a inflação calculada pelo Índice Geral de Preços - Disponibilidade Interna (IGP-DI), da Fundação Getúlio Vargas, tomando-se por ano base o último ano levantado na pesquisa ${ }^{4}$.

Este procedimento visa corrigir os preços do passado para podermos compará-los aos preços atuais, já que a taxa de inflação de nossa economia "corrói” os preços passados especialmente até 1994 de maneira muito mais intensa - e, sem essa correção, compará- 
los seria impossível, pois, variavelmente, dado o índice da inflação, eles sempre aumentam. Assim, se pode discernir um aumento inflacionário no preço de uma valorização real do imóvel.

Operacionalmente, os dados de cada cidade podem ser agrupados num mesmo modelo de planilha do software Excel®, seguindo um critério cronológico de classificação que, a partir do trabalho de digitação padronizado de cada um dos anúncios contidos nos diferentes classificados, coloquem em evidência as variáveis fundamentais à análise estatística, de forma que cada linha represente um anúncio diferente e cada coluna uma variável específica.

Ao término da digitação é dado início à segunda etapa dos procedimentos relativos ao banco de dados: a conferência dos dados compilados, a fim de evitar possíveis erros na grafia; as inconsistências entre tipos e usos, formato dos dados, dentre outros diversos problemas que possam comprometer a análise das informações registradas. Neste ponto destaca-se a importância de utilizar padronização na digitação dos dados numa mesma planilha, pois, havendo repetição de anúncio iguais, os mesmos podem ser identificados e, opcionalmente,deletados automaticamente com o recurso de exclusão de duplicatas, do software.

$\mathrm{Na}$ sequência, as duas secções prosseguem com as contribuições dos resultados de pesquisas por nós desenvolvidas, em Amorim (2011a) e Abreu(2011), respectivamente.

\section{Valorização imobiliária em Londrina/PR: o caso do mercado de terrenos urbanos}

Em pesquisa desenvolvida no âmbito do mestrado (AMORIM, 2011a) estudamos a dinâmica do mercado imobiliário londrinense sob a ótica do mercado de terrenos urbanos, das áreas de valorização e das frentes de expansão imobiliária, analisando o papel desempenhado pelo poder público local e a atuação dos principais agentes envolvidos, aprofundando em estudo de caso de uma área específica da cidade.

Para tanto, a pesquisa empírica contou com a análise da estruturação espacial da oferta de terrenos e da variação dos preços anunciados a partir de uma amostra dos terrenos ofertados no principal jornal de circulação local - a "Folha de Londrina" - durante quatro anos, a saber: 2000, 2004, 2005 e 2009, cuja escolha se justificou em função dos lançamentos de empreendimentos imobiliários que ocorriam na cidade, dentre outros motivos explicados em Amorim(2011a, p. 191-196; 2011b, p. 21). 
A partir deste levantamento apreendeu-se a variação do preço da terra urbana e suas articulações com os movimentos estruturais locais da expansão e valorização imobiliária. Com as coletas de todos os anúncios de terrenos, realizadas um domingo ao mês, e em todos os meses do ano, gerou-se um banco de dados com as variáveis, especificamente voltado à pesquisa com terrenos.

A opção por esses anos levou em conta a compreensão específica da reestruturação imobiliária na Zona Leste da cidade, que começou a ganhar ímpeto a partir de 2005, com o anúncio da construção de um complexo comercial, cultural e empresarial na área, o Complexo Marco Zero e o Boulevard Londrina Shopping, e com o início das obras no campus da Universidade Tecnológica Federal do Paraná (UTFPR).

O volume de ofertas de terrenos nos classificados de imóveis do referido jornal, além de constituir uma amostra confiável e diversificada no que diz respeito aos terrenos, mostrou-se abrangente para toda a cidade, uma vez que centraliza a maior parte de anúncios desse tipo. No entanto, deve-se ter sempre em conta que estamos lidando com um mercado no qual a disponibilidade de informação éimperfeita, considerando-se que quando se analisa classificados de jornal, por exemplo, há a possibilidade de os preços de ofertas, informados no momento inicial, diferirem dos que podem vir a se consolidar no ato final da negociação. Portanto, por comportar essa "expectativa", sempre variam com relação à média de preços anunciadas num determinado loteamento ou mesmo num bairro da cidade.

Na Tabela 1, na primeira linha, logo abaixo dos anos, dispõe-se o volume das ofertas totais anunciadas no período. Já na segunda linha, constam somente aquelas que ocorreram durante o período pesquisado sem, no entanto, serem computadas as repetições - tendo sido "deletadas" as duplicatas. Na frente dos meses, apresenta-se o volume total de todas as ofertas anunciadas, procurando então aí demonstrar sua variação mensal.

Tabela 1: Londrina. Volume de ofertas totais de terrenos nos classificados do jornal Folha de Londrina. 2000, 2004, 2005 e 2009.

\begin{tabular}{|c|c|c|c|c|}
\hline Anos: & 2000 & 2004 & 2005 & 2009 \\
\hline $\mathrm{N}^{\circ}$ de ofertas totais anunciadas & 1859 & 3542 & 4410 & 3958 \\
\hline$N^{0}$ de ofertas não repetidas & 1278 & 1811 & 2103 & 1009 \\
\hline Janeiro & 109 & 107 & 285 & 264 \\
\hline Fevereiro & 151 & 262 & 337 & 382 \\
\hline
\end{tabular}

Geo UERJ. Rio de Janeiro - Ano 16, no. 25, v.21, $2^{\circ}$ semestre de 2014, pp.297-323

ISSN: 1415-7543 E-ISSN: 1981-9021

http://www.e-publicacoes.uerj.br/index.php/geouerj 


\begin{tabular}{l|l|r|r|r|r}
\hline \multirow{7}{*}{ Meses } & Março & 88 & 201 & 422 & 360 \\
\cline { 2 - 6 } & Abril & 130 & 294 & 421 & 356 \\
\cline { 2 - 6 } & Maio & 184 & 243 & 337 & 304 \\
\cline { 2 - 6 } & Junho & 117 & 375 & 368 & 315 \\
\cline { 2 - 6 } & Julho & 165 & 323 & 434 & 340 \\
\cline { 2 - 6 } & Agosto & 195 & 358 & 393 & 318 \\
\cline { 2 - 6 } & Setembro & 198 & 338 & 326 & 349 \\
\cline { 2 - 6 } & Outubro & 208 & 308 & 380 & 331 \\
\cline { 2 - 6 } & Novembro & 170 & 352 & 372 & 316 \\
\cline { 2 - 6 } & Dezembro & 167 & 380 & 334 & 323 \\
\hline
\end{tabular}

Fonte: Folha de Londrina - Classificados - 2000, 2004, 2005 e 2009. Org. própria.

A compilação destes dados demonstra os meses com maior volume de ofertas, a partir do que poderíamos pensar na seleção de meses específicos para o levantamento dos dados, ao invés de realizá-lo durante os 12 meses do ano. Mas isso depende da disponibilidade do pesquisador, da finalidade e objetivos da pesquisa, da dimensão do mercado imobiliário da cidade e do acesso às fontes de dados.

Em relação à distribuição dessas ofertas pelas cinco zonas da cidade de Londrina constatamos, com base na Tabela 2, que aquelas de maior destaque ao longo dos quatro anos foram, para o ano 2000, as Zonas Sul e Leste; para o ano de 2004, Oeste, Sul e Leste; situação que se repete para o ano de 2005; e, finalmente, para o ano de 2009, as Zonas Leste, Oeste e Norte. Ou seja, a espacialidade da concentração das ofertas aponta áreas de interesse do mercado, áreas com presença de terrenos não edificados, frentes de expansão imobiliária e novas "fronteiras imobiliárias", seja a partir da produção de novos loteamentos ou da reestruturação de antigas e "obsoletas" áreas da cidade, e isto torna interessante, no caso londrinense, a compreensão das especificidades, do ponto de vista do mercado imobiliário, mais observáveis em cada zona.

Tabela 2: Londrina. Volume de ofertas totais de terrenos nos classificados do jornal Folha de Londrina segundo as Zonas Urbanas. 2000, 2004, 2005 e 2009.

\begin{tabular}{|c|c|c|c|c|c|c|c|c|}
\hline & \multicolumn{2}{|c|}{2000} & \multicolumn{2}{|c|}{2004} & \multicolumn{2}{|c|}{2005} & \multicolumn{2}{|c|}{2009} \\
\hline Zonas & $\mathbf{N}^{\mathbf{0}}$ & $\%$ & $\mathbf{N}^{\mathbf{O}}$ & $\%$ & $\mathbf{N}^{\mathbf{O}}$ & $\%$ & $\mathbf{N}^{\mathbf{o}}$ & $\%$ \\
\hline Centro & 169 & 13,28616 & 175 & 9,798432 & 196 & 9,386973 & 104 & 10,42084 \\
\hline Leste & 286 & 22,48428 & 431 & 24,13214 & 493 & 23,61111 & 257 & 25,7515 \\
\hline Norte & 245 & 19,26101 & 293 & 16,40538 & 355 & 17,00192 & 210 & 21,04208 \\
\hline Oeste & 253 & 19,88994 & 448 & 25,08399 & 538 & 25,76628 & 236 & 23,64729 \\
\hline Sul & 319 & 25,07862 & 439 & 24,58007 & 506 & 24,23372 & 191 & 19,13828 \\
\hline Total & 1272 & 100 & 1786 & 100 & 2088 & 100 & 998 & 100 \\
\hline
\end{tabular}

Fonte: Folha de Londrina - Classificados - 2000, 2004, 2005 e 2009. Org. própria. 
É preciso considerar que a concentração do volume de ofertas se dá em áreas específicas dessas zonas, não se distribuindo homogeneamente para o conjunto das zonas inteiras. É o caso das Zonas Sul e Oeste, em cujas intersecções estão concentradas as ofertas, formando um "vetor" exatamente no sentido sudoeste. No caso da Zona Leste, elas também se referem a determinadas áreas, situadas num setor de valorização imobiliária ali existente, próximo aos empreendimentos e instalações mencionados. Já a Zona Norte vem se destacando mais recentemente com o volume de ofertas de terrenos, o que se deve à subcentralidade urbana presente nesta área, decorrente daí a valorização da terra vinculada a este processo mais específico.

A Figura $1^{5}$ apresenta a espacialização das variáveis coletadas, demonstrando o volume de ofertas de terrenos para os anos de 2000 e 2009, em metros quadrados e em reais. É notável a valorização do preço da terra urbana que se depreende dos quatro mapas apresentados, embora existam aí fatores, tais como a inflação, conforme já explicitado. Além disso, pode-se perceber a mobilidade das ofertas, ora concentradas em determinados bairros ora em outros, demonstrando, inclusive, a concentração de terrenos vazios e a diferença em relação ao preço.Embora se verifique a valorização ainda concentrada a sudoeste, de um modo geral, a análise dos mapas apresentados na Figura 1 demonstra uma maior distribuição espacial do volume de ofertas de terrenos em 2009, em comparação com o quadro apresentando no ano de 2000.

Nas novas frentes de expansão, os negócios com terras têm maiores possibilidades de extração de maiores patamares de lucro, ocasionados pelo menor investimento na aquisição da terra e possibilidades reais de valorização em tempo hábil que remunere as frações de capital envolvidas. Áreas em que antes predominavam a presença de conjuntos habitacionais, vazios urbanos, marcadas por enormes distâncias em relação aos meios de consumo coletivo e equipamentos públicos, foram alvo, na década de 2000, de inversão de capital, investimentos públicos e abertura de novos loteamentos.

A constatação da dinâmica desse mercado, confirmada pelos próprios sindicatos do setor (Sindicato dos Corretores Imobiliários de Londrina - SINCIL, e Sindicato da Indústria da Construção Civil no Norte do Paraná - SINDUSCON-NORTE-PR), reforça a ideia da mobilidade temporal e espacial do par valorização/desvalorização imobiliária ao longo da última década, e a oscilação no montante ofertado também confirma essa tendência, conforme a análise da Figura 1. 


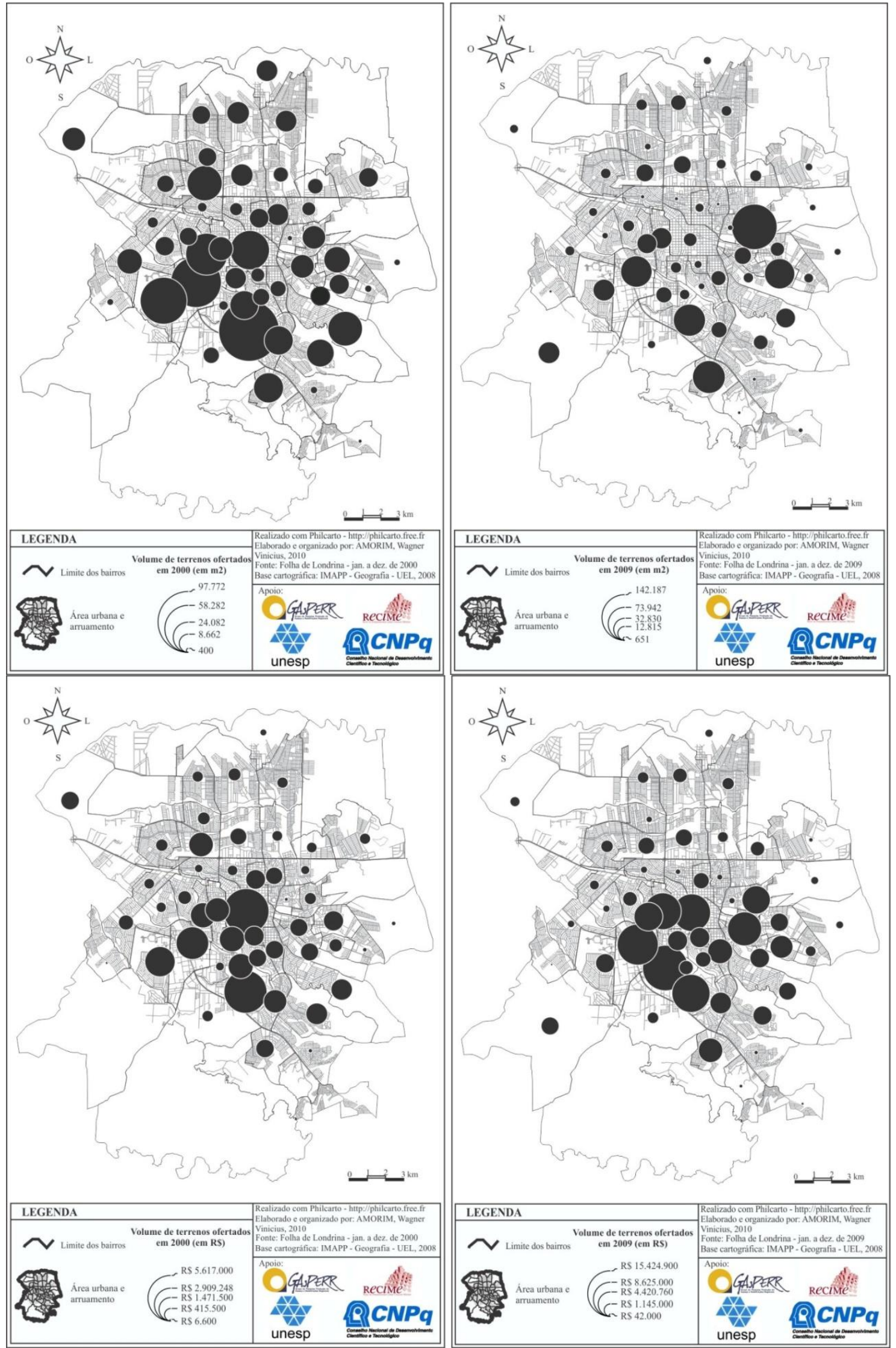

Figura 1: Londrina. Volume total de ofertas de terrenos em metros quadrados e em reais. 2000 e 2009.

Geo UERJ. Rio de Janeiro - Ano 16, nº. 25, v.21, $2^{\circ}$ semestre de 2014, pp.297-323

ISSN: 1415-7543 E-ISSN: 1981-9021

http://www.e-publicacoes.uerj.br/index.php/geouerj 
Os mapas a seguir demonstram a variação das médias de preços dos terrenos ofertados na cidade, subdividida em 55 bairros, segundo divisão adotada pela Prefeitura Municipal de Londrina (PML) e pelo Instituto de Pesquisas e Planejamento Urbano de Londrina (IPPUL).

A subdivisão da cidade de Londrina em "bairros" foi desenvolvida segundo uma tipologia da PML, que leva em conta as semelhanças socioeconômicas e os nomes dos bairros mais populares e conhecidos, que herdam nomes atribuídos às glebas em que foi subdividida a terra no início da ocupação. Logo abaixo das zonas (Norte, Sul, Leste, Oeste e Centro), os referidos "bairros" agrupam setores censitários do IBGE - como também vilas, jardins, residenciais, conjuntos habitacionais, parques industriais, loteamentos e condomínios fechados etc. -, a partir de uma estruturação 'reconhecida' e 'aceita' pelos londrinenses, de acordo com o IPPUL (AMORIM, 2011a, p. 50).

Pode-se constatar o preço médio dos terrenos dividindo a soma do preço em reais pela soma do volume em metros quadrados para cada bairro. Por fim, para a distribuição das classes de preços nos mapas apresentados na Figura 2, utilizamos a técnica de amplitude de classes (produto do número de valores pelo número de classes), demonstrando classes com o mesmo número de unidades espaciais (cinco e/ou seis ocorrências para cada classe), mantendo-se as proporções, situando-se as médias intraclasses e minimizando-se o desvio padrão.O conjunto dos quatro mapas demonstra um grande salto na amplitude dos preços no período 2005 e 2009.

Nos mapas referentes aos anos de 2000 e 2004 essa amplitude situava-se entre R\$ 10 e $\mathrm{R}$ \$ 208, e entre R\$ 15 e R\$292, respectivamente, no preço médio do metro quadrado de terreno para o conjunto dos bairros, embora nem todos dispusessem de anúncios nos períodos analisados.

Já nos anos de 2005 e 2009 essa amplitude situou-se entre R \$ 20 e R \$ 357, e entre R\$ 34 e R \$ 869, respectivamente. Nem todos os bairros dispunham de informações no que se refere às ofertas de terrenos, nem todos os bairros possuíam terrenos à venda, o que, no caso dos bairros mais periféricos, condiz com a existência de vazios urbanos não loteados, e com poucos casos de anúncios de chácaras de grandes dimensões à venda. Embora, mais se perceba a concentração da valorização nas áreas centrais e adjacências, desponta um "vetor" de valorização imobiliária no sentido sudoeste e, com menor intensidade, em alguns bairros a leste do centro. 




Figura 2: Londrina. Preço médio de terrenos ofertados nos classificados. 2000, 2004, 2005 e 2009.

Geo UERJ. Rio de Janeiro - Ano 16, no. 25, v.21, $2^{\circ}$ semestre de 2014, pp.297-323

ISSN: 1415-7543 E-ISSN: 1981-9021

http://www.e-publicacoes.uerj.br/index.php/geouerj 
Vale ressaltar que os preços utilizados para a confecção destes mapas não foram deflacionados, trabalho que fizemos a parte, na dissertação de mestrado, em tabelas, comparando os preços anunciados e seus correlatos inflacionados dos anos anteriores, auferindo, então, aqueles que ficaram acima ou abaixo do preço inflacionado. Evidenciou-se que nem todas as áreas apresentaram valorização no preço da terra para os anos de 2000, 2004 e 2005. Na verdade, na maioria dos bairros os preços não atingiam sequer seus correlatos inflacionados, sendo, portanto, uma valorização altamente seletiva e concentrada. Muitos proprietários, independentemente de seus objetivos, possuíam verdadeiros ativos que se depreciavam em função da dinâmica espacial imobiliária da cidade concentrada e segmentada. Já no período 2005-2009 o que se verificou foi uma intensa valorização dos terrenos em quase toda a cidade, sendo poucos os bairros que apresentavam médias de preços abaixo dos preços corrigidos, confirmando a grande intensidade das expectativas com os empreendimentos e negócios imobiliários por toda a cidade nesse período(AMORIM, 2011, p. 215-225, 246-247, 286-287).

\section{O mercado imobiliário em Londrina/PR, Marília/SP e São José do Rio Preto/SP: uma análise comparativa}

O relato de caso que ora apresentamos tem por objetivo a exposição das possibilidades de análise decorrentes da abordagem metodológica que parte da base de dados oriunda dos classificados de jornal, privilegiando uma análise comparada entre diferentes cidades, que neste caso são Marília/SP, São José do Rio Preto/SP e Londrina/PR. Para tanto, as informações subsequentes foram extraídas de Abreu (2011) e atendem basicamente a duas preocupações norteadoras. A primeira relaciona-se à elaboração de um material capaz de estabelecer indicadores que permitam a caracterização do mercado imobiliário em sua estrutura e organização intraurbana. A segunda é referente ao potencial comparativo, permitindo verificar similaridades e diferenças entre os mercados imobiliários de cada cidade.

Para tanto, foram coletados os dados presentes nos anúncios de classificados dos jornais locais de maior circulação de cada cidade estudada, nos anos de 1995, 2000 e 2006. Na cidade de Marília o jornal utilizado foi o "Diário de Marília”, em São José do Rio Preto, o jornal "Diário da Região", em Londrina, o jornal utilizado foi a "Folha de Londrina". 
A disposição dos dados orienta-se de modo a permitir uma melhor percepção dos diferentes tipos de imóveis e da distribuição dos preços segundo sua localização, seus usos e agentes ofertantes, tornando possível a percepção de sua ocorrência em diferentes áreas da cidade.

Para isso, a organização do banco de dados tomou os seguintes procedimentos para organização e análise das informações: a) os percentuais referentes à quantidade dos tipos de imóveis ofertados, divididos em bairros e por zonas urbanas (norte, sul, centro, leste e oeste); b) as variações gerais dos preços do $\mathrm{m}^{2}$ dos tipos de imóveis; c) as amplitudes e a moda dos preços coletados para cada zona; d) a elaboração cartográfica dos resultados obtidos; e,e) o potencial comparativo.

$\mathrm{O}$ primeiro item traz a organização primária dos dados, referente à sua divisão percentual de ofertas por tipo de imóveis: apartamentos (A), casas $(C)$ e terrenos $(T)$, na totalidade de imóveis coletados, destacando sua variação e frequência no conjunto da cidade, sendo possível observar a oscilação e maior ocorrência na oferta de cada imóvel em específico para o período considerado.

Encontram-se na Tabela 3 os resultados obtidos com os anúncios de jornal, para a cidade de Marília, em que se adota uma subdivisão de zonas urbanas estabelecida pelo plano diretor local, sendo ela a Central, Centro-Leste, Centro-Oeste, Centro-Norte e Centro-Sul, Norte, Sul Leste e Oeste.

Tabela 3: Marília. Variação em valores percentuais do número de ofertas segundo o tipo de imóvel. 1995, 2000 e 2006.

\begin{tabular}{|c|c|c|c|c|c|c|c|c|c|}
\hline \multirow{2}{*}{$\begin{array}{l}\text { Total de } \\
\text { anúncios }\end{array}$} & \multicolumn{3}{|c|}{1995} & \multicolumn{3}{|c|}{2000} & \multicolumn{3}{|c|}{2006} \\
\hline & $\mathbf{A}$ & $\mathbf{C}$ & $\mathbf{T}$ & $\overline{\mathbf{A}}$ & $\mathbf{C}$ & $\mathbf{T}$ & $\overline{\mathbf{A}}$ & $\mathrm{C}$ & $\mathbf{T}$ \\
\hline Central & $2,97 \%$ & $6,46 \%$ & $0,45 \%$ & $1,78 \%$ & $3,62 \%$ & $0,13 \%$ & $6,06 \%$ & $2,45 \%$ & $0,58 \%$ \\
\hline Centro-Leste & $1,90 \%$ & $0,14 \%$ & $0,00 \%$ & $3,05 \%$ & $0,06 \%$ & $0,00 \%$ & $0,11 \%$ & $0,11 \%$ & $0,62 \%$ \\
\hline Centro-Oeste & $0,93 \%$ & $1,31 \%$ & $0,93 \%$ & $0,76 \%$ & $2,54 \%$ & $1,65 \%$ & $1,39 \%$ & $1,39 \%$ & $0,99 \%$ \\
\hline Centro-Norte & $2,00 \%$ & $4,83 \%$ & $1,80 \%$ & $5,40 \%$ & $2,98 \%$ & $0,63 \%$ & $6,02 \%$ & $6,02 \%$ & $0,00 \%$ \\
\hline Centro-Sul & $3,21 \%$ & $0,14 \%$ & $0,07 \%$ & $8,06 \%$ & $0,51 \%$ & $0,25 \%$ & $9,71 \%$ & $0,58 \%$ & $0,00 \%$ \\
\hline Leste & $0,69 \%$ & $10 \%$ & $6,94 \%$ & $0,38 \%$ & $19,68 \%$ & $11,62 \%$ & $0,29 \%$ & $21,90 \%$ & $7,59 \%$ \\
\hline Oeste & $0,21 \%$ & $6,39 \%$ & $7,94 \%$ & $0,63 \%$ & $4,38 \%$ & $4,38 \%$ & $0,07 \%$ & $3,39 \%$ & $1,35 \%$ \\
\hline Norte & $0,66 \%$ & $7,32 \%$ & $6,49 \%$ & $0,00 \%$ & $6,98 \%$ & $5,02 \%$ & $0,04 \%$ & $8,07 \%$ & $3,47 \%$ \\
\hline Sul & $0,52 \%$ & $16 \%$ & $10 \%$ & $0,32 \%$ & $11,11 \%$ & $4,06 \%$ & $0,11 \%$ & $12,15 \%$ & $1,86 \%$ \\
\hline Média \% & $13 \%$ & $52 \%$ & $35 \%$ & $20 \%$ & $52 \%$ & $28 \%$ & $27 \%$ & $56 \%$ & $16 \%$ \\
\hline
\end{tabular}

Fonte: Banco de Dados de anúncios imobiliários.Org.própria. 
Delimitada a localização dos imóveis, buscou-se a caracterização da dinâmica geral e variação dos preços médios por bairros e zonas no período compreendido, considerando sua dinâmica de valorização e desvalorização de preços. A série histórica construída atendeu necessariamente a critérios bem definidos para a utilização e o descarte dos dados compilados, já que esta foi construída apenas com anúncios completos que permitiam uma comparação primária por bairros, e subsequentemente por zonas.

Esta classificação é necessária visto que alguns anúncios não dispõem de informações suficientes quanto aos itens preço e área - do terreno ou construída -, inviabilizando sua análise. Outros, porém, já não dispõem de pares nos anos subsequentes, isto é, alguns bairros podem ser anunciados unicamente num ano especifico, não mantendo uma continuidade nos anos sucessivos.

Além de permitir sua organização em tabelas, este arranjo possibilita a elaboração de gráficos que sintetizam a variação do preço do metro quadrado para cada bairro em comparação com a média geral de preços no total da zona. Para exemplificar, utilizaremos o produto gráfico elaborado para análise da cidade de Marília (Gráfico 1), referente à Zona Leste e também o Gráfico 2 referente a Zona Sul da cidade de Londrina.



Gráfico 1: Marília. Variação do preço nominal/real do $\mathrm{m}^{2}$ dos terrenos na Zona Leste. 1995, 2000 e 2006.

Fonte: Banco de Dados de anúncios imobiliários. Org. própria.

Deste arranjo desdobram-se diferentes análises possíveis, abarcando a constatação da evolução do preço de um mesmo bairro no período considerado, assim como sua posição em relação ao restante da zona urbana em que está inserido e, numa análise

Geo UERJ. Rio de Janeiro - Ano 16, no. 25, v.21, $2^{\circ}$ semestre de 2014, pp.297-323

ISSN: 1415-7543 E-ISSN: 1981-9021

http://www.e-publicacoes.uerj.br/index.php/geouerj 
mais abrangente, em relação ao restante da cidade.Além disso, permite a análise comparada entre as cidades (Gráfico 2).

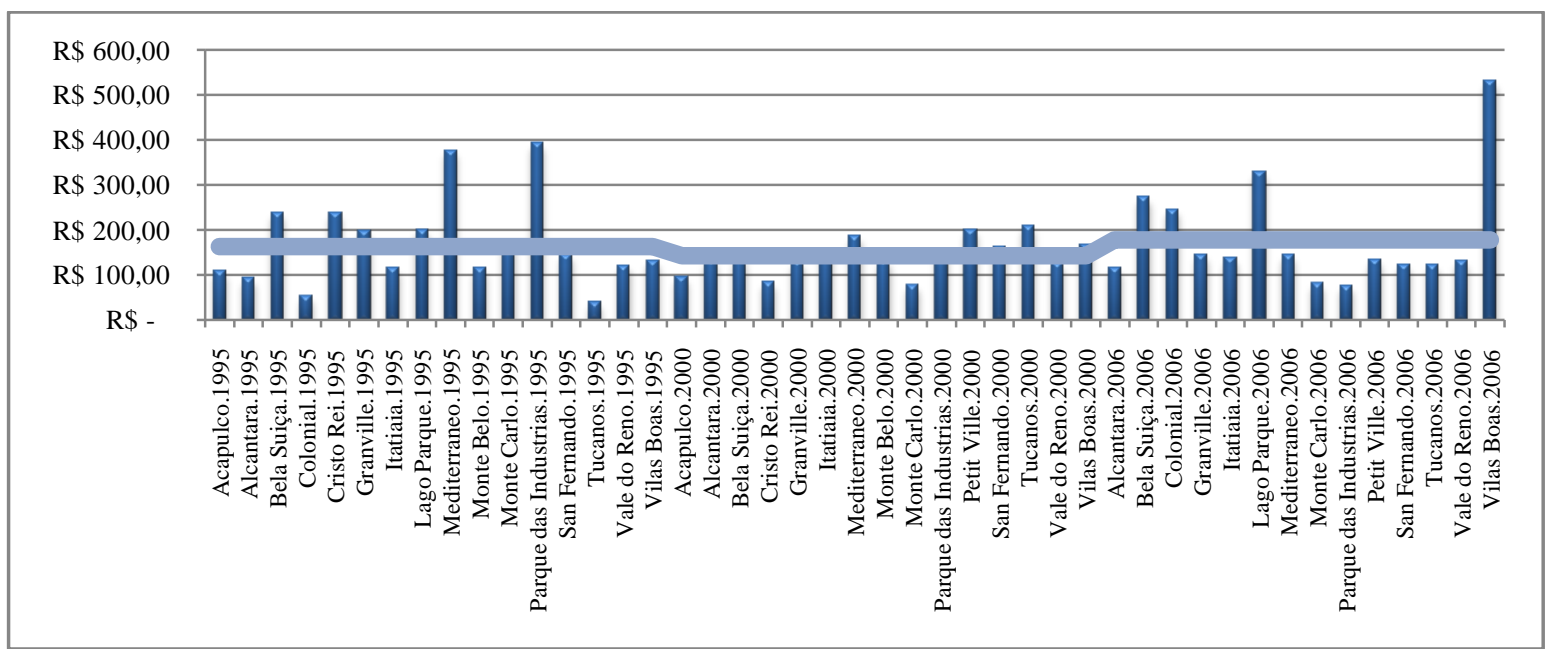

Gráfico 2: Londrina. Variação do preço nominal/real do $\mathrm{m}^{2}$ dos terrenos na Zona Sul. 1995, 2000 e 2006.

Fonte: Banco de Dados de anúncios imobiliários. Org. própria.

Buscando o recurso da comparação, a organização dos gráficos apresentados prioriza a eleição de indicadores capazes de evidenciar os eixos de valorização, a diferenciação dos preços ao longo dos anos e a forma como esta variação se comporta no interior das cidades e, além disso, se os setores de maior e menor valorização indicam similaridades quanto à variação dos preços médios e a seletividade imposta em diferentes zonas.

Ademais, como um recurso alternativo para a organização dos dados, já que não é possível contar sempre com a totalidade de informações necessárias à constituição de um quadro completo para todos os tipos de imóveis, é válida a elaboração destes a partir das amplitudes e da moda dos preços médios em cada zona.

Com a caracterização da amplitude dos preços de oferta dos tipos de imóveis, faz-se sinalizar e identificar o padrão de ocupação em cada área, ou seja, verificar o perfil de cada zona através da homogeneidade ou heterogeneidade de seus preços, além de perceber a variação dos preços entre os imóveis mais ofertados no período analisado. Complementarmente, o recurso estatístico da moda (Tabela 4) permite visualizar o padrão dos imóveis comercializados em relação à amplitude e a variação entre os anos. 
Tabela 4: São José do Rio Preto. Variação entre os menores, maiores e a moda de preços em $\mathrm{m}^{2}$ das casas. 1995, 2000 e 2006.

\begin{tabular}{l|r|r|r|r|r|r|r|r|r}
\hline & \multicolumn{4}{|c|}{1995} & \multicolumn{3}{|c|}{ 2000 } & \multicolumn{3}{c}{2006} \\
\cline { 2 - 11 } & Meno & \multicolumn{1}{|c|}{ Maior } & Moda & Meno & Maio & Moda & Meno & Maior & Moda \\
\hline Centra & 75,74 & 358,03 & 252,4 & 160,0 & 360,6 & 189,1 & 18,80 & 325,49 & 218,8 \\
\hline Leste & 66,73 & 577,63 & 188,0 & 51,59 & 383,9 & 136,5 & 65,64 & $1.620,0$ & 109,4 \\
\hline Norte & 21,66 & 97,78 & 81,48 & 88,61 & 207,5 & 207,5 & 91,90 & $1.458,6$ & 105,0 \\
\hline Oeste & 46,38 & 254,62 & 71,14 & 127,1 & 350,8 & 128,1 & 86,33 & 269,77 & 127,6 \\
\hline Sul & 11,46 & $2.406,7$ & 104,2 & 77,38 & 517,3 & 281,5 & 8,53 & $1.531,6$ & 169,2 \\
\hline
\end{tabular}

Fonte: Banco de Dados de anúncios imobiliários. Org. própria.

O destaque dado às formas de representação das variáveis até aqui caracterizadas valorizou as potencialidades existentes na representação dos imóveis ofertados, em sua localização e preço. Para isso, dispomos de recursos gráficos - tais como tabelas e gráficos - para sua representação. De modo auxiliar é possível ainda destacar as formas de representação cartográfica

Um problema comum na delimitação deste recurso analítico remete ao recorte empregado para cada cidade, ensejando na problemática da espacialização/zoneamento mais adequado. A partir das experiências desenvolvidas ao longo da elaboração da monografia de conclusão de curso, Abreu (2011) indica os empecilhos existentes à subdivisão por bairros, isto porque, são poucas as cidades que dispõem de leis específicas e/ou mapas atualizados sobre divisões territoriais em bairros. Desta forma, a resolução destes problemas encontra saída em recortes comuns denominados como "zonas urbanas", atendendo a critérios específicos de cada prefeitura, favorecendo assim a espacialização dos dados no interior da malha urbana.

Utilizaremos as representações elaboradas para a cidade de Marília, conforme destacada na Figura 3, em que está exposta a subdivisão por zonas - Norte, Leste, Oeste, Sul, Centro Norte, Centro Leste, Centro Oeste e Centro Sul - e as ofertas dos tipos de imóveis nos anos de 1995, 2000 e 2006, respectivamente.

Este conjunto de mapas foi elaborado a partir das ferramentas disponíveis pelo software de mapeamento e análise geográfica Mapinfo®, resultantes da associação entre os dados coletados em jornal e as bases cartográficas das cidades, disponibilizadas pelo Centro de Estudos e Mapeamento da Exclusão Social para Políticas Públicas (CEMESP), da FCTUNESP. 


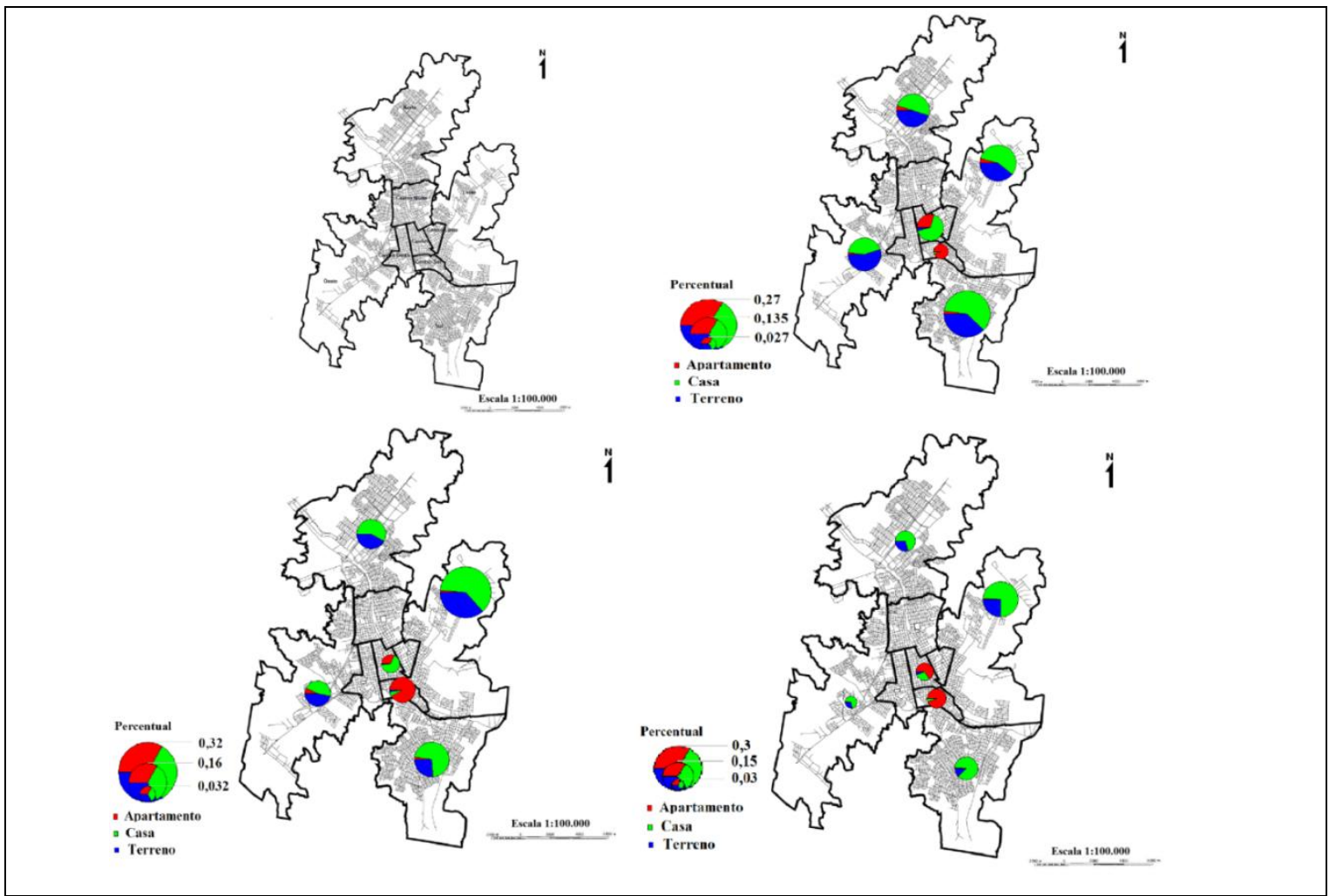

Figura 3: Marília. Zonas urbanas e estruturação das ofertas imobiliárias entre os anos 1995, 2000 e 2006.

Fonte: Banco de Dados de anúncios imobiliários. Base Cartográfica: Lei do Plano Diretor da Cidade de Marília.

A representação cartográfica da cidade de Marília toma por base as configurações extraídas da Lei do Plano Diretor Local (Lei Complementar nº 480 de 09 de Outubro de 2006). Esta lei produziu uma proposta de agregação dos distintos bairros em nove zonas urbanas - Norte, Sul, Leste, Oeste, Centro-Sul, Centro-Norte, Centro-Oeste e CentroLeste. Para tanto as informações estão dispostas em seu valor percentual, buscando evidenciar a variação do volume de ofertas para cada tipo de imóvel no interior da cidade.

A primeira representação condiz à subdivisão por zonas utilizadas para a espacialização dos anúncios segundo os critérios adotados pelo plano diretor, conforme já destacado. Subsequentemente optamos pela exposição dos dados, dispostos através de uma relação entre a oferta de apartamentos, casas e terrenos na totalidade de imóveis coletados, destacando sua variação diferencial no conjunto da cidade e a oscilação da oferta de cada imóvel em específico, sendo eles 1995, 2000 e 2006, respectivamente. 
Por fim, um último procedimento de análise associado a esta base de dados está atrelado ao seu potencial comparativo. A construção desta discussão é assumida a partir da opção de análise de diferentes cidades sob uma série histórica que conjugue diferentes anos. Os parâmetros para esta investigação são, portanto, a identificação das articulações entre as permanências das velhas formas urbanas e as transformações reconhecidas pela oscilação dos preços dos imóveis e do tipo de imóvel ofertado ao longo da série histórica.

\section{Considerações finais}

O teor das pesquisas aqui expostas convida ao debate em torno das preocupações presentes desde a coleta e sistematização de informações direcionadas à análise do mercado imobiliário em cidades médias.

Desdobram-se deste debate o interesse e a necessidade de se reconhecer, distinguir e avaliar as diferentes fontes de dados empíricos disponíveis, assim como as formas de organização deste material, os caminhos possíveis e as questões pertinentes para a construção de uma abordagem ampla e capaz de oferecer uma leitura espacial da dinâmica imobiliária.

A partir deste direcionamento enfatizou-se o tratamento das informações extraídas dos anúncios presentes em classificados de jornal. A escolha deste recurso não se dá aleatoriamente, mas atende a um exame metódico e criterioso quanto a sua proveniência, riqueza de informações e o acesso facilitado. Para isso, sua análise deve ser precedida de questões pertinentes à seleção do material, orientando assim a classificação destas informações, e a devida escolha das diferentes variáveis.

Nesta abordagem metodológica as questões “o quê? Aonde? Quando? E a que custo?” oferecem possibilidades classificatórias elencadas em diferentes variáveis que são capazes de incorporar-se a um enquadramento amplo, a partir do qual se estabeleçam informações qualificadas e de fácil correlação entre as variáveis selecionadas, favorecendo um conjunto de investigações que se desdobram em análises comparadas tanto no plano intraurbano, ou mesmo numa comparação entre cidades.

Conforme exemplificado com os estudos de Amorim (2011a) e Abreu (2011), a escolha desta fonte de dados habilita um conjunto extenso de possibilidades analíticas a partir de diferentes temáticas articuladas ao estudo do mercado imobiliário. Oferece condições 
para a composição de uma série histórica em que é possível perceber as mudanças e as permanências encontradas na dinâmica intraurbana, a partir da oscilação dos preços, do ganho de importância de alguns produtos imobiliários, de agentes de comercialização etc. Ademais, permite estudos comparados entre cidades, colaborando, assim, para a compreensão das formas de estruturação deste mercado, das estratégias despendidas em cada cidade e em diferentes contextos socioespaciais. A espacialização dos anúncios representa outra vantagem para com esta fonte de dados, pois possibilita a representação cartográfica destes eventos.

Ressaltamos ainda a necessidade de um projeto cartográfico que vem da conjugação dos levantamentos realizados, do esforço analítico e, principalmente, da forma deinterpretação e de exposição dos resultados, devendo estar presente em todas as etapas da pesquisa e que possa ser mais que mera representação dos resultados, ou seja, um instrumento de leitura da realidade em transformação. Isto requer a compreensão da espacialidade do objeto da pesquisa, dos múltiplos recortes que podem ser adotados, dos conflitos - temporais e espaciais - existentes entre a dinâmica imobiliária e a subdivisão oficial/institucional da cidade, ou entre diferentes cidades quando se tratar de um estudo comparativo.

São estas as ideias que presidem nossa intervenção às questões pertinentes as fontes de dados capazes de compor um estudo adequado da oferta imobiliária, reconhecendo, contudo, suas limitações, mas buscando superar as dificuldades colocadas pela ausência de informações sistematizadas e de dados oficiais.

A evidência que persiste, ao fim destas análises, possibilita algumas reflexões e hipóteses, direcionadas pela articulaçãoindissociável entre a escassez e as irregularidades para com as fontes de dados e a própria constituição e estruturação deste mercado.

Trata-se de um mercado em que a ausência de informações sistematizadas e confiáveis compõe sua própria lógica de funcionamento e organização interna. A opacidade e insuficiência de informações atualizadas e de fácil acesso sobre os tipos, localizações, preços e tributos recolhidos em cada uma das transações imobiliárias parecem associarse as estratégias destes agentes, visto que estas informações circulam de maneira restrita, favorecendo alguns poucos agentes, oferecendo, assim, condições para o 
controle da apropriação da valorização imobiliária e dos processos especulativos em períodos e áreas especificas.

\begin{abstract}
Notas:
${ }^{1}$ Este artigo corresponde aos resultados finais de pesquisas realizadas pelos autores em âmbito de monografia de bacharelado (ABREU, 2011) e dissertação de mestrado (AMORIM, 2011a). Foi apresentado sob a forma de "oficina" durante do X Workshop da Rede de Pesquisadores sobre Cidades Médias (ReCiMe), realizado na Universidade Estadual Paulista, campus de Presidente Prudente/SP, durante os dias 14 e 16 de agosto de 2012.

${ }^{2}$ Uma melhor sistematização das diferentes etapas da pesquisa à luz dos procedimentos metodológicos pode ser encontrada em Sposito (2003), as quais estão delimitadas em quatro momentos distintos: Compilatória, Correlatória, Semântica e Normativa.

${ }^{3}$ As peculiaridades deste mercado atreladas a natureza da mercadoria, as formas de negociação, tais como, localização e durabilidade quando associada ao imóvel, ou a imprescindível base fundiária e o longo tempo de rotação do capital investido são investigadas em Melazzo (1993, 1997, 2010), Topalov (1979), Smolka (1987) e Sposito (1990), dentre outros.

${ }^{4}$ O IGP-DI, responsável por avaliar a evolução geral de preços na economia, cria uma medida da inflação nacional, sendo composto pelo Índice de Preços ao Consumidor (IPC - peso de 30\%), Índice de Preços no Atacado (IPA - peso de 60\%) e Índice Nacional de Construção Civil (INCC - peso de 10\%). O período de coleta de preços para o índice é o mês cheio, ou seja, do primeiro ao último dia do mês. Fonte: http://www.igf.com.br/aprende/glossario/glo_Resp.aspx?id=1602). Para extrair o índice base para o calculo do $\mathrm{m}^{2}$ utilizamos a calculadora do cidadão, ferramenta disponibilizada no site do Banco Central, no seguinte endereço:

htts://www3.bcb.gov.br/CALCIDADAO/publico/corrigirPelaSelic.do?method=corrigir PelaSelic

${ }^{5}$ Todos os mapas apresentados nesta secção do texto foram elaborados com o software livre Philcarto. Para um necessário estudo do programa Philcarto, indicamos os seguintes trabalhos basilares na utilização do software e conhecimento das abordagens e procedimentos da cartografia temática: Girardi (2007) e Archela e Théry (2008), além, é claro, dos próprios manuais de autoajuda e visita guiada que acompanham o software em seu endereço eletrônico de download: http://philcarto.free.fr/.
\end{abstract}

\title{
Referências:
}

ABRAMO, Pedro. A dinâmica imobiliária. Elementos para o entendimento da espacialidade urbana. Cadernos IPPUR, Rio de Janeiro, ano III, No especial, dez. 1989.

ABREU, Marlon A. O mercado imobiliário em Londrina, Marília e São José do Rio Preto: análise comparativa do processo de estruturação intra-urbano. 2011. $136 \mathrm{f}$. Trabalho de Conclusão de Curso (Bacharelado em Geografia), Departamento de Geo UERJ. Rio de Janeiro - Ano 16, $\mathrm{n}^{\circ}$. 25, v.21, $2^{\circ}$ semestre de 2014, pp.297-323

ISSN: 1415-7543 E-ISSN: 1981-9021

http://www.e-publicacoes.uerj.br/index.php/geouerj 
Geografia, Universidade Estadual Paulista - Faculdade de Ciências e Tecnologia de Presidente Prudente, 2011. Disponível em:

http://pt.scribd.com/doc/146140518/Monografia-Marlon-2011-Versao-Final. Acessado em 05 de junho de 2013.

AMORIM, Wagner V.A produção social do espaço urbano em Londrina - PR: a valorização imobiliária e a reestruturação urbana. 2011. 287f. Dissertação (Mestrado em Geografia), Programa de Pós-Graduação em Geografia, Universidade Estadual Paulista - Faculdade de Ciências e Tecnologia de Presidente Prudente, 2011a. Disponível em: http://www2.fct.unesp.br/pos/geo/dis teses/11/ms/wagner.pdf. Acessado em 06 de junho de 2013.

Reestruturação urbana e valorização imobiliária em Londrina - PR. Revista da ANPEGE, Fortaleza, V. 7 № 7, p. 13-29, 2011b. Disponível em:

http://anpege.org.br/revista/ojs-2.2.2/index.php/anpege08/article/view/125/RA7g.

Acessado em 23 de julho de 2014.

ARCHELA, Rosely S.; THÉRY, Hervy. Orientação metodológica para construção e leitura de mapas temáticos. Confins, Paris, v. 3, p. 1-14, 2008. Disponível em: http://confins.revues.org/3483. Acessado em 23 de julho de 2014.

CESARE, Cláudia M. de; CUNHA, Eglaísa M. P. Base de dados: preços praticados. In: Avaliação em Massa de Imóveis para Fins Fiscais. Discussão, Análise e Identificação de Soluções para Problemas e casos Práticos. Brasília: Ministério das Cidades - Lincoln Institute of Land Policy, 2012. Disponível em:

http://www.capacidades.gov.br/biblioteca/detalhar/id/266/titulo/Avaliacao+em+Massa+ de+Imoveis+para+Fins+Fiscais. Acessado em 05 de junho de 2013.

GIRARDI, Eduardo P. Manual de utilização do programa Philcarto 4.XX para Windows. Presidente Prudente: [s.n.], 2007. Disponível em:

http://www2.fct.unesp.br/nera/atlas/downloads.htm. Acessado em 05 de junho de 2013. 
MELAZZO, Everaldo S. Mercado imobiliário, expansão territorial e transformações intra-urbanas: o caso de Presidente Prudente - SP. 1993. 144f. Dissertação (Mestrado em Planejamento Urbano e Regional), Instituto de Pesquisa e Planejamento Urbano e Regional, Universidade Federal do Rio de Janeiro, 1993.

. Expansão Territorial e Estruturação do Espaço Urbano: Referências Teóricas. Cadernos do Departamento de Planejamento, Presidente Prudente, № 2, 1997.

Dinâmica imobiliária e processos de estruturação intra-urbana em cidades de porte médio: hipóteses e propostas de trabalho. Anais do XVI Encontro Nacional de Geógrafos - Crise, práxis e autonomia: espaços de resistência e de esperanças, XVI ENG, Associação de Geógrafos Brasileiros, Porto Alegre - RS, 2010. Disponível em:

http://www.agb.org.br/evento/download.php?idTrabalho=4500. Acessado em 23 de julho de 2014.

Escalas e agentes, processos e projetos: análise comparativa da dinâmica imobiliária no Brasil. Anais do XVII Encontro Nacional de Geógrafos - Entre escalas, poderes, ações, Geografias, XVII ENG, Associação de Geógrafos Brasileiros, Belo Horizonte - MG, 2012. Disponível em: http://www.eng2012.org.br/trabalhoscompletos?download=1514:edp-texto-completo-eng-2012-everaldomelazzo\&start=780. Acessado em 23 de julho de 2014.

SMOLKA, Martin O. O capital incorporador e seus movimentos de valorização. Cadernos IPPU, Rio de Janeiro, Ano II, Nº 1, jan/abr. 1987.

SPOSITO, Eliseu S. Produção e apropriação da renda fundiária urbana em Presidente Prudente. 1990. 230 f. Tese (Doutorado em Geografia). Programa de Pós-Graduação em Geografia Humana, Universidade de São Paulo.

Geografia e Filosofia. Contribuição para o Ensino do Pensamento Geográfico. São Paulo: Ed. Unesp, 2003.

TOPALOV, Christian. Análise do ciclo de reprodução do capital investido na produção da indústria da construção civil. Capital e Propriedade Fundiária. In: FORTI, Reginaldo (org.). Marxismo e urbanismo capitalista. São Paulo: Editora Ciências Humanas, 1979. 
Artigo recebido para publicação em março de 2014.

Artigo aceito para publicação em outubro de 2014

Geo UERJ. Rio de Janeiro - Ano 16, nº. 25, v.21, $2^{\circ}$ semestre de 2014, pp.297-323

ISSN: 1415-7543 E-ISSN: 1981-9021

http://www.e-publicacoes.uerj.br/index.php/geouerj 